\title{
Dyslexic students: from language learning to language testing
}

\section{Pelleriti, Margherita}

Language Centre, University of Modena and Reggio Emilia, Italy.

\begin{abstract}
This paper will focus on the delicate issue of assessing the language proficiency of dyslexic students in a foreign language, namely English. These learners are usually considered a sub-group of test takers because of their specific learning differences. An overview of dyslexia will be presented, shedding light on the difficulties encountered by dyslexic students during their learning process. Some of the accommodations used during the learning process will be illustrated, along with the accommodations and/or modifications allowed during language testing. Attention will also be paid to fairness and validity represented by accommodations. Moreover, the special requirements allowed by international examination boards during their highstakes tests will be analysed. Finally, this paper will illustrate what the Italian Law takes into account for dyslexic students and how it is applied at the University of Modena and Reggio Emilia, Italy.
\end{abstract}

Keywords: dyslexia; SpLDs; language testing; learning differences; accommodations; testing validity. 


\section{Dyslexia: a brief overview}

Dyslexia has only recently received the due attention it deserves and it is now internationally recognised, also thanks to accredited associations, such as British Dyslexia Association (http://www.bdadyslexia.org.uk/), European Dyslexia Association (http://www.eda-info.eu/), International Dyslexia Association (https://dyslexiaida.org/). Dyslexia is a neurological disorder, a genetic, inherited condition, so probably it has always existed but in the past nobody was able to recognise and, consequently, diagnose it (http://www.bdadyslexia.org.uk/). Dyslexia is not a disease - so there is no cure for it - and it is not concerned with psychology, as pointed out in the BDA's website. Dyslexia is one manifestation of what is known as "specific learning difficulties" (SpLDs) and according to the BDA, it is quite common (about $10 \%$ of the population in the United Kingdom). Furthermore, there are different grades of severity - what Turner and Pughe (2003) call the "continuum of dyslexia" (pp. 5-6) -, so that each single case should be individually observed and analysed.

However, some features are common to all dyslexic students: difficulties in attention control, reduced working memory, difficulties in reading (Turner \& Pughe, 2003). Reading aloud can be extremely challenging for them, especially if they are also expected to understand the meaning of what they are reading. Seymour (2005, as cited in Mortimore et al., 2012) points out that such a difficulty is even more severe in languages which are not transparent, such as English. Dyslexic students have problems with sound-letter association also in their L1, consequently this hurdle can become even harder for them in L2. In English, for instance, Davies and Richie (2003, as cited in Mortimore et al., 2012) remind us that there are 44 phonemes which are represented by more than 120 graphemes. Dyslexic students also find very challenging to remember new vocabulary and to learn grammatical rules. They can benefit a lot from multi-sensory teaching (Schneider \& Crombie, 2003; Turner \& Pughe, 2003), for example involving body movements and touch, since kinaesthetic-tactile learning helps them stay focused, catching their attention and increasing their chance of storing and retrieving information (Schneider \& Crombie, 2003). Finally, accuracy in spelling remains a big hurdle for dyslexic students who can be helped if they are explicitly taught how and why letters relate one another. Such an understanding will provide support in order to predict the most probable way to spell a word (Turner \& Pughe, 2003).

\section{Dyslexic students and accommodations}

Students with SpLDs and their specific needs have long been neglected. Only recently they have received more attention, also thanks to the efforts by the European Commission in order to make language examinations accessible to students with specific learning 
differences. Such a need has become even stronger considering the important social impact language examinations have, since in Europe they are also used as prerequisites for being admitted to university, graduating, getting a job (Kormos \& Smith, 2012). Despite their difficulties, dyslexic students can be helped by adopting some accommodations, which are alterations - previously approved - to the default testing conditions (Hansen, Mislevy, Steinberg, Lee, \& Forer, 2005). These modifications are only meant to bridge the gap by removing the barriers encountered during their foreign language learning process and related assessment, since those hurdles are unfair to dyslexic students due to their neurological deficit.

Butler and Stevens (1997, as cited in Li \& Suen, 2012) distinguish two major categories of accommodations: the first concerns modifying the test (e.g., assessing in the native language, reducing linguistic complexity, providing additional examples), whereas the second requires modification of the test procedure (e.g., granting extra testing time, administering the test in separate rooms/in small groups/in several sessions, allowing breaks during the test, reading aloud).

Kormos and Smith (2012) prefer to make a distinction between accommodations and modifications, depending on the impact they have on the test construct. In particular, accommodations will not badly affect the construct of the test, whilst modifications will have an adverse impact on its validity. An example of modification can be represented by the read aloud arrangement to dyslexic students in a reading comprehension test. If the focal construct includes the ability to decode a text, then reading aloud will unfairly advantage that sub-group of test takers.

Bearing these distinctions in mind, there are several ways to help dyslexic students. For instance, if they are asked to perform a reading comprehension task, the passage can be divided into shorter bits or the reading text as a whole can be shortened. Comprehension questions should not contain grammatical structures which are notably considered harder for dyslexic students, such as the use of passive forms. Moreover, they should be asked to demonstrate they are able to look for key information (reading for gist), as opposed to searching for specific content (reading for detail). In addition, since their sight can also be concerned because of blurred vision, justified texts should be avoided for dyslexic students and they should be provided with texts written not only in larger fonts and with more spacing, but also on coloured paper. As a matter of fact, the background colour (as opposed to the usual white paper) helps dyslexic students to better distinguish letters and their contours (BDA's website). Should the text be administered on a computer, it would be possible to provide monitor overlays (BDA's website). Considered their difficulties in attention control, dyslexic students should be allowed frequent supervised breaks and, whenever possible, they should be assessed in a very quiet place with no or very limited distracting elements. In addition, they should also be allowed extra time to perform a task, 
especially because students with SpLDs sometimes use part of the extended time in order to just understand the task instructions (Kormos \& Smith, 2012).

When asked to write, dyslexic students should not be penalised for their often illegible handwriting and/or for spelling mistakes. Dyslexic students could therefore be provided with word processors and spell checkers. Nonetheless, whenever possible, it would be better to transform the writing task into an oral production (Kormos \& Smith, 2012), even if also spoken language can be problematic for dyslexic students. As a matter of fact, they need more time and energy in order to formulate their thoughts, so it would be advisable to avoid the straightforward question-and-answer method. This means that dyslexic students should not be put under pressure and that they should be allowed some time in order to prepare their answers, even if they are delivered orally (Turner \& Pughe, 2003).

As far as listening comprehension is concerned, this is a very challenging task for dyslexic students because of the difficulties they face with it. For instance, dyslexic students have reduced phonemic awareness, consequently it is hard for them to perceive differences between sounds, such as long vowels against short ones (Turner \& Pughe, 2003); it is difficult for them to remember longer bits of conversation, so that it would be better to shorten the listening passages, exactly as it happens with reading comprehension (Kormos \& Smith, 2012). It is even more challenging if dyslexic students are expected to listen to a passage and answer the related questions at the same time, especially if they are open-ended (Kormos \& Smith, 2012). In this case, the possible accommodations to adopt might be represented by asking dyslexic students questions in their native language and by allowing them to answer again in their native language. This is something similar to the dual language version of a test, as referred by Abedi (2014). Furthermore, answers might also be provided orally, where open-ended questions are expected, or by administering multiplechoice items, provided that they are not negatively formulated or particularly and deliberately tricky. Finally, considered their shorter memory span and their reduced attention control, dyslexic students should be allowed to perform listening comprehension tasks in separate rooms, far from any potential distraction.

In order to accommodate students with special needs, computers have been used more and more thanks to their versatility and flexibility. Their use is now widespread also in tests, since technology can help solve several accessibility issues which still remain in paper-andpencil tests (Kormos \& Smith, 2012). The advantages computers can offer concern, for instance, the opportunity to provide several accommodations to be employed at the same time and within the test itself, including the adjustment of the font size on the computer screen or self-voicing applications. In addition, computer-based tests allow consistency and uniformity in delivering the accommodations required (e.g., read-aloud) in order to satisfy the individual needs of each single user (Abedi, 2014). This is even more evident when human readers are asked to read aloud the options of a given item, since they might 
emphasise the right answer, giving unintentional cues to the students, altering the construct of what is being measured (Abedi, 2014). Moreover, in computer-based tests, dyslexic students will not be required to transfer their answers on separate answer sheets, avoiding the risk of potential mistakes while transferring their answers (Kormos \& Smith, 2012).

Finally, it is worth noticing that Thompson, Johnstone, and Thurlow (2002) have tried to suggest a universal test design for large-scale assessment. Their idea is that tests should be designed with disabled learners in mind; in this way, since tests would be more flexible and hence appropriate for any student, accommodations would be no more necessary. Unfortunately, considering the great variety of disabilities, their different levels of severity, the heterogeneity in test takers with their strengths (e.g., sometimes they can also somehow compensate for a deficit) and weaknesses, the universal test design might not be the solution to specific learning difficulties. Consequently, individualised considerations when granting accommodations are highly recommended (Kormos \& Smith, 2012).

\section{Accommodations and testing validity}

Accommodations have also represented a very big concern for assessors and language testers, since they might undermine the fairness and validity of assessment and language testing (Hansen et al., 2005). As a matter of fact, accommodations should not give dyslexic students an advantage over their fellow students who are not allowed to use them. Accommodations should only be a fair opportunity for dyslexic students to show their knowledge and ability (Hansen et al., 2005; Li \& Suen, 2012).

$\mathrm{Li}$ and Suen (2012) compared the effects of test accommodations on the test performance of both English Language Learners (ELLs) and non-ELLs. They applied a meta-analysis using hierarchical linear modelling, which revealed that test accommodations had positive effects only on ELLs (i.e., their test performance was improved), whereas the non-ELLs outcomes were substantially unaffected by the accommodations. This is exactly the way accommodations should work in order to be considered valid, by levelling the playing field only for those students somehow concerned by a deficit. Such a behaviour is also known as "interaction hypothesis", that is, valid accommodations will improve the scores only for the students who need them, leaving unaffected the outcomes of those students who do not necessitate accommodations (Hansen et al., 2005, p. 110).

Abedi (2014) mentions some studies on computer-based assessments with accommodations, such as extra testing time, read aloud, option to modify font size. The results showed that the test validity was not compromised, since the focal construct was unaltered and therefore preserved. 
Hansen et al. (2005) try to define their target population, since for a validity argument sensitive to test accessibility it is of paramount importance to recognise the many differences which exist within the several populations of test takers. Then, Hansen et al. (2005) identify the knowledge, skills, and other attributes (KSAs) they need for their study, making a clear distinction between focal and ancillary KSAs. The status of being focal or ancillary depends on the definition of the targeted proficiency; consequently, a KSA may be focal for a given targeted proficiency and ancillary for another. Focal KSAs cannot be modified, whereas it is possible to change ancillary requirements in order to make a test more accessible to disadvantaged students. Furthermore, since defining the targeted proficiency is a deliberate choice, this means that for validity issues all test takers will be assessed against that same definition, independently of any disability or deficit they might have.

\section{International examination boards and accommodations}

Depending on the severity of their disorder and their level of motivation, dyslexic students can represent potential test takers for international examination boards. This is why the latter have contemplated the opportunity for students with special needs to require accommodations.

Kormos and Smith (2012) have analysed the accommodations provided by Cambridge ESOL (at the time of their writing), TOEFL iBT, Pearson Educational Tests. They have pointed out that some accommodations are commonly shared, such as the ones concerning the response format, the use of a word processor, of a scribe, of extra testing time, of supervised breaks, and of transparent coloured overlays.

The author of the present paper has also investigated other international examination boards, namely Trinity College London (Trinity) and IELTS. Concerning Trinity, they have devoted a web page (http://www.trinitycollege.com/site/?id=2933) to special needs requests, where they state the importance of treating each student individually and of avoiding any form of discrimination, while preserving the quality of their examinations at the same time. Candidates are only asked to send all the relevant supporting documentation at least 28 days before the examination date. Should the information provided not be satisfactory, the request for accommodations may be refused.

IELTS (https://www.ielts.org/book-a-test/special-requirements) also state they make every effort in order to accommodate test takers with special needs and a whole web page (https://www.ielts.org/book-a-test/special-requirements/learning-difficulties) is devoted to specific learning difficulties, like dyslexia; in particular, extra time, supervised breaks, computer, enlarged print copies are mentioned as arrangements. However, compared to 
Trinity, they need a longer notice period - six weeks for the extra time and three months for a modified version of the test. Finally, it is worth noticing they state that spelling and grammar mistakes are marked in the same way as all other test takers.

\section{Dyslexia in Italy}

In Italy there is a national association (https://www.aiditalia.org/) which deals with SpLDs and dyslexia is recognised by the Law No. 170 promulgated in 2010 (http://www.istruzione.it/esame_di_stato/Primo_Ciclo/normativa/allegati/legge170_10.pdf) - According to the guidelines provided in 2011 by the Italian Ministry of Education, University and Research

(MIUR) (http://www.miur.gov.it/documents/20182/198444/Linee+guida+per+il+diritto+allo+studio +degli+alunni+e+degli+studenti+con+disturbi+specifici+di+apprendimento/663faecdcd6a-4fe0-84f8-6e716b45b37e), special accommodations must be offered to dyslexic students, also during evaluation and assessment, including high-stakes tests. For instance, they can be allowed the use of information technology (such as word processors, electronic dictionaries), of 30\% extra time (a percentage defined "reasonable" by the Ministry), and they can also be granted reduced workload (e.g., less exercises, shortened version of a test), although preserving the same standards in terms of quality. As far as foreign languages are concerned, the guidelines include a section (i.e., 4.4) devoted to them. In particular, whenever possible, they recommend choosing a more transparent foreign language and oral communication should be privileged. Furthermore, if deemed necessary because of very severe dyslexia and/or comorbidity, dyslexic students may also be exempted from studying a foreign language (MIUR Decree No. 5669/2011, http://www.istruzione.it/esame_di_stato/Primo_Ciclo/normativa/allegati/prot5669 11.pdf). Nevertheless, this may represent a controversial issue, since further education of dyslexic students might be compromised due to a different school leaving certificate - as stated in the Decree Law No. 62/2017, Article 20, Clause 13 (http://www.gazzettaufficiale.it/eli/id/2017/05/16/17G00070/sg) - which denies them the right to enroll at university.

At the University of Modena and Reggio Emilia (UNIMORE), there is an office (http://www.asd.unimore.it/site/home.html) devoted to help and guide dyslexic students. They submit their supporting documentation to that office and they have interviews with the people working there. During their academic career, they are also tutored by peer and senior students who are previously trained by specialised University staff. It is plausible to deduce that learners with SpLDs attending university (i.e, higher education which is not mandatory in Italy) should not be very severe dyslexic students. Although the rules and regulations of the Italian Law are applied, it is worth noting that these are usually general 
and standardised, while each learner with SpLDs is an individual with his/her own peculiarities, strengths and weaknesses. As a consequence, despite the big efforts already made by the office, whose work is also well appreciated nationwide, the support service for dyslexic students might be improved by promoting more awareness and dialogue with the lecturers dyslexic students will encounter during their academic career, as recommended by Kormos and Smith (2012), while preserving the quality standards of academic learning and examinations. Such a need becomes even stronger when a foreign language, namely English which is compulsory in every course of studies, should be assessed. UNIMORE is also the project leader of the European Erasmus+ project "TIDE - new Tools for Inclusion of Dyslexic studEnts" (https://project-tide.eu/), aiming at collecting best practice and writing guidelines for inclusion of dyslexic students, in particular from school to university in order to promote their advances and success in higher education (i.e., a higher rate of dyslexic students attending university and graduating).

\section{Conclusions}

Dyslexia has only recently received the attention it deserves. Despite their neurological disorder, dyslexic students can succeed in activities such as reading, learning a foreign language, but also passing exams and graduating. This can be made possible thanks to some accommodations only meant to avoid a bias towards this particular group of learners and/or test takers, avoiding at the same time to provide an unfair advantage to them.

The accommodations provided to dyslexic students during a test could be compared to the metaphor of eyeglasses. There are some people who need to wear them because of a deficit in their sight; in this way, they can continue to drive safely, to read, to watch TV. Nevertheless, the simple fact of wearing eyeglasses does not mean that the world (i.e., the test construct) is different and that people who do not need to wear them will be somehow disadvantaged or advantaged in what and how they can see around them (i.e., the test). As a consequence, eyeglasses (i.e., accommodations) will only make the world and everyday activities accessible to the individuals (i.e., dyslexic students) who need them, removing the barriers that a deficit in sight might cause.

In conclusion, further research (especially on accommodations and validity issues) and more awareness would be needed and advantageous. This would also be beneficial in order to promote more inclusion of dyslexic students in higher education. 


\section{References}

Abedi, J. (2014). The use of computer technology in designing appropriate test accommodations for English Language Learners. Applied Measurement in Education, 27 (4), 261-272. doi: 10.1080/08957347.2014.944310

Hansen, E. G., Mislevy, R. J., Steinberg, L. S., Lee, M. J., \& Forer, D. C. (2005). Accessibility of tests for individuals with disabilities within a validity framework. System, 33, 107-133. doi: 10.1016/j.system.2004.11.002

Kormos, J., \& Smith, A. M. (2012). Teaching languages to students with specific learning differences. Clevedon, UK: Multilingual Matters.

Law No. 170. (2010). Retrieved April 29, 2018, from http://www.istruzione.it/esame_di_stato/Primo_Ciclo/normativa/allegati/legge170_10.p df

Li, H., \& Suen, H. K. (2012). Are test accommodations for English language learners fair? Language Assessment Quarterly, 9(3), 293-309. doi: 10.1080/15434303.2011.653843

MIUR. (2011). Decreto Ministeriale N. 5669 del 12 luglio 2011. Retrieved April 29, 2018, from

http://www.istruzione.it/esame_di_stato/Primo_Ciclo/normativa/allegati/prot5669_11.p $\underline{\mathrm{df}}$

MIUR. (2011). Linee guida per il diritto allo studio degli alunni e degli studenti con disturbi specifici di apprendimento. Retrieved April 29, 2018, from

http://www.miur.gov.it/documents/20182/198444/Linee+guida+per+il+diritto+allo+stu dio+degli+alunni+e+degli+studenti+con+disturbi+specifici+di+apprendimento/663faec d-cd6a-4fe0-84f8-6e 716b45b37e

Mortimore, T., Hansen, L., Hutchings, M., Northcote, A., Fernando, J., Horobin, L., et al. (2012). Dyslexia and Multilingualism: Identifying and supporting bilingual learners who might be at risk of developing SpLD/dyslexia. Retrieved April 29, 2018, from https://www.bdadyslexia.org.uk/common/ckeditor/filemanager/userfiles/About_Us/Proj ects/Big_Lottery_Research_Report_Final_Version.pdf

Schneider, E., \& Crombie, M. (2003). Dyslexia and foreign language learning. London: David Fulton Publishers.

Thompson, S. J., Johnstone, C. J., \& Thurlow, M. L. (2002). Universal design applied to large scale assessments (Synthesis Report 44). Minneapolis, MN: University of Minnesota, National Center on Educational Outcomes. Retrieved April 29, 2018, from http://www.cehd.umn.edu/nceo/onlinepubs/synthesis44.html

Turner, E., \& Pughe, J. (2003). Dyslexia and English. London: David Fulton Publishers. 